\section{Oil and Fatty Acid Composition of Tepary Bean Seed}

\author{
Harbans L. Bhardwaj ${ }^{1}$ and Anwar A. Hamama \\ Agricultural Research Station, Virginia State University, P.O. Box 9061, \\ Petersburg, VA 23806
}

\begin{abstract}
Information about oil and fatty acids in tepary bean (Phaseolus acutifolius A. Gray) seed, a promising alternative crop for the mid-Atlantic region of U.S., is largely unknown. Such information is needed to assess the food and feed potentials of tepary bean seed. We determined the concentrations of oil and fatty acids in seed produced by eight tepary bean genotypes planted at three different dates each during 1997 and 1998 at Ettrick, Va. Tepary bean seeds contained $1.8 \%$ oil as compared to literature values of $1.3 \%, 1.1 \%$, and $1.1 \%$ for navy, kidney, and pinto beans, respectively. Tepary bean seed oil contained $33 \%$ saturated, $67 \%$ unsaturated, $24 \%$ monounsaturated, and $42 \%$ polyunsaturated fatty acids. Planting dates and genotypes did not affect oil concentration. Neb-T-14 was identified to be a desirable genotype based on a low concentration of saturated and a high concentration of polyunsaturated fatty acids. Based on concentrations of oil and fatty acids, tepary bean seeds compared well with those of navy, kidney, and pinto beans.
\end{abstract}

Tepary bean is a short-life-cycle annual desert legume indigenous to northwestern Mexico and the southwestern U.S. (Nabhan, 1983; Nabhan andFelger, 1978). This crop plant, highly tolerant to heat and drought stresses, produce nutritious, high protein seed that is suitable for human consumption (Miklas et al., 1994; Thomas et al., 1983). Tepary bean has the potential to aid in crop diversification efforts and for ensuring availability of food grains in areas where drought is a common occurrence. Tepary bean may also have a special significance as a short-season crop in agricultural systems which could benefit from a short-duration crop to produce food and feed grains. We have previously demonstrated the feasibility of tepary bean production as a short season summer crop that may be suitable for rotation with winter wheat (Bhardwaj et al., 2002).

More recently, we reported that tepary bean seeds contained $24 \%$ protein as compared to reported average values of $22.3 \%$ in navy, $22.5 \%$ in red kidney, and $20.9 \%$ in pinto bean and have potential as food and feed (Bhardwaj and Hamama, 2004).

Even though issues related to production and protein and mineral composition of tepary bean seed produced in the mid-Atlantic region have been addressed, information regarding concentrations of oil and fatty acids in tepary bean seed is unknown. Such information is needed to assess the potential of tepary bean seed as a food and feed since lipids in seed of food crops serve as a source of energy, as a structural component of cell membranes in the form of phospholipids, and also affect human and livestock health based on concentrations of saturated, unsaturated, and essential fatty acids. In addition, effects of production practices,

Received for publication 9 Aug. 2004. Accepted for publication 16 Jan. 2005. Contribution of Virginia State University, Agricultural Research Station,Journal Article Series No. 242. The use of any trade names or vendors does not imply approval to the exclusion of other products or vendors that may also be suitable.

${ }^{1}$ Corresponding author; e-mail hbhardwj@vsu.edu. geographical location, and variation among tepary bean genotypes for these traits have not been characterized. The objectives of our studies were to determine the concentrations of oil and fatty acids in tepary bean seeds and to characterize the variation in these traits due to genotypes and planting dates. We were also interested in comparing the oil and fatty acid concentrations in tepary bean seed to that in other common food legumes.

\section{Materials and Methods}

Seeds of eight tepary bean genotypes (NebT-3, Neb-T-4, Neb-T-5, Neb-T-8, Neb-T-9, Neb-T-11, Neb-T-14, and Neb-T-15), supplied by Dermot P. Coyne, University of Nebraska, Lincoln, were used in these studies. These eight genotypes were planted on three dates each in 1997 (29 May, 19 June, and 10 July) and 1998 (30 May, 22 June, and 10 July) at Randolph Farm of Virginia State University, located in Ettrick, Virginia (370-15' N and 0770-30.8'W). Each experiment consisted of three replicates per planting date (randomized complete block design). Limited quantities of seed necessitated the use of single rows in 1997 when we used a breeding line of soybean, similar in height and size to tepary bean, to plant guard rows with each tepary bean row to avoid border effects. However, during 1998, all plots consisted of three rows. Therows were $6 \mathrm{~m}$ long with between row spacing of $75 \mathrm{~cm}$.

About 200 seeds, without any seed treatment, were planted in each row with a cone-type planter at a depth of about $2.5 \mathrm{~cm}$. These plots received no fertilizer or irrigation applications. The soil for these plots was kept fallow during experimental location was Abel sandy loam (FineLoamy mixed thermic Aquatic Hapludult). The weeds in these plots were controlled manually. All plots received one application of permethrin ( $60 \mathrm{~g} \cdot \mathrm{ha}^{-1}$ a.i. of Ambush). At maturity, in early October during both years, plots (middle rows only during 1998) were harvested, and dry seeds from all replications the previous fall season. The soil type at the of a genotype in each planting date were bulked to save resources. For the determination of oil and fatty acid concentrations, we only used one sample from each bulk.

The oil was extracted from $5 \mathrm{~g}$ of ground seed at room temperature by homogenization for 2 min in $15 \mathrm{~mL} 3$ hexane : 2 isopropanol (v/v) with a tissue homogenizer (model 985-370; Biospec Products, Inc. Racine, Wis.) and centrifuged at $4000 \mathrm{~g}_{\mathrm{n}}$ for $5 \mathrm{~min}$, as described by Bhardwaj and Hamama (2000). The oil extraction was repeated three times for each sample to ensure full oil recovery and the three extractions were combined. The hexane-lipid layer was washed and separated from the combined extract by shaking and centrifugation with $10 \mathrm{~mL}$ of $1 \%$ $\mathrm{CaCl}_{2}$ and $1 \% \mathrm{NaCl}$ in $50 \%$ methanol. The washing procedure was repeated and the purified lipid layer was removed by aspiration and dried over anhydrous $\mathrm{Na}_{2} \mathrm{SO}_{4}$. The oil concentrations (percent of seed, dry weight basis) were determined gravimetrically after drying under vacuum at $40^{\circ} \mathrm{C}$ and stored under nitrogen at $-10^{\circ} \mathrm{C}$ until analysis.

Fatty acid methyl esters (FAMEs) were prepared by an acid-catalyzed transestrification method as described by Bhardwaj and Hamama (2000) and Dahmer et al. (1989). The oil samples $(5 \mathrm{mg})$ were vortexed with $2 \mathrm{~mL} 1$ sulfuric acid: 99 methanol (v/v) in 10-mL glass vials containing a Teflon boiling chip. The open vials were placed in a heating block at $90{ }^{\circ} \mathrm{C}$ until the sample volume was reduced to 0.5 $\mathrm{mL}$. After cooling to room temperature, $1 \mathrm{~mL}$ of hexane followed by $1 \mathrm{~mL}$ of distilled water, were added. The mixture was vortexed and the upper hexane layer containing the FAME was taken and dried over anhydrous $\mathrm{Na}_{2} \mathrm{SO}_{4}$. The hexane phase containing FAME was transferred to a suitable vial and kept under $\mathrm{N}_{2}$ at $0{ }^{\circ} \mathrm{C}$ for gas chromatographic analysis.

Analyses of FAME were carried out as described by Bhardwaj and Hamama (2000), using a SupelcoWax 10 capillary column (25 $\mathrm{m} \times 0.25 \mathrm{~mm}$ i.d. and $0.25 \mathrm{~m}$ film thickness, SupelcoWax, Inc., Bellefonte, Pa.) in a gas chromatograph equipped with a flame ionization detector (FID) (model Vista 6000; Varian, Sugar Land, Texas). An integrator (SP-4290; Spectra Physics, San Jose, Calif.) was used to determine relative concentrations of the detected fatty acids.

Peaks were identified by reference to the retention of FAME standards and quantified by the aid of heptadecanoic acid (17:0) as an internal standard. The concentration of each fatty acid was calculated as a percentage $(\mathrm{w} / \mathrm{w})$ of the total fatty acids.

All data were analyzed by procedures in version 6.11 of SAS (SAS, 1996). The seed composition data were analyzed by using year $\times$ entry $\times$ planting date mean squares as the error term (Steel and Torrie, 1980). The oil traits of seeds produced by Virginia-grown teparies were compared to the literature values (USDA, 2004) for navy, kidney, and pinto beans.

\section{Results and Discussion}

Concentrations of oil in tepary bean seeds were not affected by genotypes or planting dates 
(Table 1). Planting date had a significant effect on concentrations of 18:2,20:1, total saturated, total unsaturated, and poly-unsaturated fatty acids (Table 1 ). Tepary bean genotypes differed significantly for 16:0, 18:0, 22:0, 24:0, $18: 2$, total saturated, total unsaturated, and polyunsaturated fatty acids (Table 1). Most of the two-way interactions involving year, planting date, and genotype were nonsignificant. However, two-way interactions between planting date and genotype for all these traits were nonsignificant. Given that we were mostly interested in planting dates and genotypes, means of planting dates, for concentrations of oil and various fatty acids, are presented over years and genotype and those of genotype are presented over years and planting dates. In the case of concentrations of 20:1 and 22:0 fatty acids only, mean comparisons were made separately over years. It was not possible to test three-way interactions in our studies.

The oil concentration in seeds of eight tepary bean genotypes, grown in Virginia, varied from 1.6 to 1.9 with a mean of $1.8 \%$ (Table 2 ). The literature values for oil concentration of tepary bean produced in southwestern U.S. range from $0.4 \%$ to $1.9 \%$ indicating that tepary bean produced in Virginia are similar to those produced in the southwestern U.S. Planting date only affected the concentrations of 18:2,20:1, saturated, unsaturated, and polyunsaturated fatty acids in the seed oil of tepary bean. The lowest concentrations of 18:2 and polyunsaturated fatty acids were associated with planting done in mid-June whereas plantings done in late May or mid-July resulted in increased concentrations. The highest concentrations of 20:1 and saturated, and lowest concentrations of unsaturated fatty acids occurred in planting done in mid-June (Table 2).

Delay in planting from mid-June to mid-July resulted in significant reduction in saturated fatty acids and significant increase in the concentration of unsaturated fatty acids (Table 2). In general, human diet containing lower concentration of saturated and higher concentration of unsaturated fatty acids is considered healthy (Morris, 2004; Watkins, 2004), therefore, planting of tepary bean later in the summer may be desirable.
The eight tepary bean genotypes did not differ in concentrations of oil, 20:0, 16:1, 18:1, $18: 3,20: 1$, and monounsaturated fatty acids. The highest concentration of saturated fatty acids was observed in the seed oil of Neb-T-3 (37.5\%) whereas the highest concentrations of unsaturated and poly-unsaturated fatty acids ( $70.8 \%$ and $45.4 \%$, respectively) were found in Neb-T-14. The highest concentration of linoleic fatty acid (18:2 or Omega-6) was found in the seed oil of Neb-T-14 (34.8\%). The tepary bean genotypes didn't differ significantly for the concentration of 18:3 (Omega-3) fatty acid. It is worthwhile to note that linoleic acid (18:2) and Linolenic acid (18:3) are essential fatty acids for human nutrition. There is increasing evidence that the ratio of Omega- 3 to Omega- 6 in the human diet plays an important role in the development of many degenerative diseases (Shukla and Bhattacharya, 2004).

Because of significant year $\times$ planting date and year $\times$ genotype interactions for concentrations of 20:1 and 22:0 fatty acids, data were analyzed separately by years (Data not presented). During 1997, planting done on

Table 1. Analysis of variance (mean squares) for concentrations of oil (percent of seed, dry weight basis) and fatty acids (percent of total fatty acids, w/w) in seed of eight tepary bean genotypes grown at three planting dates in Virginia during 1997 and 1998.

\begin{tabular}{|c|c|c|c|c|c|c|c|c|}
\hline Trait & $\mathrm{Y}^{\mathrm{z}}$ & $\mathrm{PD}^{\mathrm{z}}$ & $\mathrm{G}^{\mathrm{z}}$ & $\mathrm{Y} \times \mathrm{PD}$ & $\mathrm{Y} \times \mathrm{G}$ & $\mathrm{PD} \times \mathrm{G}$ & R square & $\mathrm{CV}(\%)$ \\
\hline$\overline{\text { Oil }}$ & $9.46^{* * *}$ & 0.30 & 0.08 & 0.35 & 0.09 & 0.19 & 89.62 & 19.51 \\
\hline $16: 0$ & $24.20^{*}$ & 10.03 & $20.10^{\text {*** }}$ & 5.39 & 1.98 & 2.54 & 80.78 & 8.77 \\
\hline $18: 0$ & $76.15^{* *}$ & 0.86 & $2.99^{* *}$ & 0.74 & 0.64 & 0.55 & 92.88 & 12.78 \\
\hline $20: 0$ & 0.90 & 1.30 & 0.23 & $1.87^{*}$ & 0.48 & 0.37 & 74.46 & 42.74 \\
\hline $22: 0$ & $5.80^{* * *}$ & 0.00 & $0.27^{\text {*** }}$ & $0.27^{*}$ & $0.19^{*}$ & 0.06 & 92.30 & 25.40 \\
\hline $24: 0$ & 0.24 & 0.23 & $0.34^{*}$ & 0.36 & 0.19 & 0.17 & 86.18 & 21.10 \\
\hline $16: 1$ & $28.29^{* * *}$ & 2.74 & 0.23 & 2.26 & 0.20 & 0.82 & 81.90 & 77.36 \\
\hline $18: 1$ & $4668.51^{* * *}$ & 0.95 & 4.95 & 4.27 & 7.03 & 4.16 & 99.15 & 7.75 \\
\hline $18: 2$ & $2347.94^{* *}$ & $22.34^{*}$ & $13.85^{*}$ & 14.56 & 4.69 & 3.26 & 97.94 & 6.28 \\
\hline $18: 3$ & $1694.68^{* *}$ & 8.05 & 6.26 & $15.30^{*}$ & 1.40 & 3.30 & 97.90 & 15.47 \\
\hline $20: 1$ & $10.25^{\text {*** }}$ & $1.26^{*}$ & 0.15 & $1.35^{*}$ & 0.23 & 0.17 & 83.54 & 70.51 \\
\hline $\mathrm{SFA}^{\mathrm{y}}$ & $182.60^{* * *}$ & $17.66^{*}$ & $34.23^{\text {*** }}$ & 9.97 & 2.22 & 3.65 & 89.82 & 6.28 \\
\hline USFA $^{x}$ & $182.40^{* * *}$ & $17.64^{*}$ & $34.20^{\text {*** }}$ & 9.98 & 2.22 & 3.65 & 89.83 & 3.15 \\
\hline MUFA $^{w}$ & $5793.93^{* *}$ & 5.51 & 5.99 & 1.09 & 9.43 & 4.37 & 99.06 & 8.32 \\
\hline PUFA $^{\mathrm{v}}$ & $8031.60^{* * *}$ & $40.97^{* * *}$ & $14.94^{*}$ & 6.36 & 5.89 & 1.97 & 99.28 & 4.89 \\
\hline
\end{tabular}

${ }^{\mathrm{z}} \mathrm{Y}=$ years; $\mathrm{PD}=$ planting date ; and $\mathrm{G}=$ genotypes.

ySaturated fatty acids.

xUnsaturated fatty acids

wono-unsaturated fatty acids

voly-unsaturated fatty acids

${ }^{*, * *}$ Significant at $5 \%$ and $1 \%$ level, respectively.

Table 2. Concentrations of oil (percent of seed, dry weight basis) and fatty acids (percent of total fatty acids, w/w) in seed of eight tepary bean genotypes grown at three planting dates in Virginia during 1997 and 1998.

\begin{tabular}{|c|c|c|c|c|c|c|c|c|c|c|c|c|c|c|c|}
\hline $\mathrm{PD}^{\mathrm{z}}$ & Oil & $16: 0$ & $18: 0$ & $20: 0$ & $22: 0$ & $24: 0$ & $16: 1$ & $18: 1$ & $18: 2$ & $18: 3$ & $20: 1$ & $\mathrm{SFA}^{\mathrm{y}}$ & USFA $^{\mathrm{x}}$ & MUFA $^{w}$ & PUFA $^{v}$ \\
\hline Late-May & 1.94 & 22.89 & 6.40 & 1.31 & 0.99 & 1.49 & 1.62 & 21.91 & 32.08 & 10.33 & 0.72 & 33.20 & 66.80 & 24.40 & 42.40 \\
\hline Mid-June & 1.74 & 24.19 & 6.02 & 1.85 & 0.97 & 1.44 & 1.12 & 22.40 & 30.12 & 10.59 & 1.06 & 34.58 & 65.42 & 24.71 & 40.71 \\
\hline Mid-July & 1.68 & 22.75 & 5.99 & 1.41 & 0.99 & 1.26 & 0.80 & 22.21 & 32.25 & 11.67 & 0.50 & 32.52 & 67.48 & 23.57 & 43.91 \\
\hline $\operatorname{LSD}(0.05)$ & NS & NS & NS & NS & NS & NS & NS & NS & 1.50 & NS & 0.41 & 1.59 & 1.59 & NS & 1.57 \\
\hline \multicolumn{16}{|l|}{ Genotypes } \\
\hline Neb-T-3 & 1.93 & 25.51 & 7.72 & 1.50 & 1.07 & 1.63 & 1.16 & 20.87 & 30.31 & 9.41 & 0.59 & 37.53 & 62.47 & 22.74 & 39.72 \\
\hline Neb-T-4 & 1.58 & 23.75 & 6.03 & 1.31 & 0.69 & 1.10 & 1.18 & 22.57 & 31.36 & 11.00 & 0.67 & 33.03 & 66.97 & 24.61 & 42.36 \\
\hline Neb-T-5 & 1.92 & 23.61 & 5.64 & 1.62 & 1.00 & 1.37 & 1.26 & 21.92 & 30.62 & 11.92 & 0.78 & 33.39 & 66.61 & 24.06 & 42.55 \\
\hline Neb-T-8 & 1.72 & 22.46 & 6.13 & 1.59 & 0.83 & 1.09 & 1.53 & 22.67 & 30.10 & 12.68 & 0.51 & 32.21 & 67.79 & 25.01 & 42.78 \\
\hline Neb-T-9 & 1.76 & 22.79 & 6.06 & 1.40 & 0.91 & 1.58 & 1.15 & 22.78 & 31.68 & 10.62 & 0.81 & 32.89 & 67.11 & 24.81 & 42.30 \\
\hline Neb-T-11 & 1.76 & 24.00 & 6.40 & 1.82 & 1.41 & 1.74 & 1.26 & 22.10 & 30.70 & 10.52 & 0.91 & 34.49 & 65.51 & 24.29 & 41.22 \\
\hline Neb-T-14 & 1.74 & 19.43 & 5.76 & 1.70 & 0.89 & 1.27 & 1.06 & 23.51 & 34.77 & 10.58 & 0.87 & 29.15 & 70.84 & 25.48 & 45.36 \\
\hline Neb-T-15 & 1.86 & 24.65 & 6.35 & 1.26 & 1.03 & 1.37 & 0.83 & 20.98 & 32.29 & 10.16 & 0.95 & 34.76 & 65.24 & 22.79 & 42.45 \\
\hline $\operatorname{LSD}(0.05)$ & NS & 2.53 & 0.97 & NS & 0.31 & 0.36 & NS & NS & 2.45 & NS & NS & 2.60 & 2.60 & NS & 2.57 \\
\hline Mean & 1.79 & 23.28 & 6.14 & 1.53 & & 1.39 & 1.18 & 22.18 & 31.48 & 10.86 & & 33.43 & 66.57 & 24.22 & 42.34 \\
\hline
\end{tabular}

zPD: Planting date.

${ }^{\mathrm{y}}$ Saturated fatty acids.

${ }^{x}$ Unsaturated fatty acids.

${ }^{\mathrm{w}}$ Monounsaturated fatty acids.

vPolyunsaturated fatty acids. 
Table 3. Concentrations of oil (percent of seed, dry weight basis) and fatty acids (percent of total fatty acids, w/w) in seed of eight tepary bean genotypes grown at three planting dates in Virginia during 1997 and 1998 as compared to the literature values for navy, kidney, and pinto beans. ${ }^{\mathrm{z}}$

\begin{tabular}{|c|c|c|c|c|c|}
\hline \multirow[b]{2}{*}{ Variable } & \multicolumn{2}{|c|}{ Tepary bean } & \multirow{2}{*}{$\begin{array}{l}\text { Navy } \\
\text { bean }\end{array}$} & \multirow{2}{*}{$\begin{array}{c}\text { Kidney } \\
\text { bean }\end{array}$} & \multirow{2}{*}{$\begin{array}{l}\text { Pinto } \\
\text { bean }\end{array}$} \\
\hline & VA-grown ${ }^{2}$ & Literature $^{\mathrm{y}}$ & & & \\
\hline$\overline{\text { Oil }}$ & $1.8(1.6-1.9)$ & $0.4-1.9$ & 1.3 & 1.1 & 1.1 \\
\hline $16: 0$ & $23.3(18.4-28.6)$ & --- & 24.2 & 12.8 & 20.3 \\
\hline $18: 0$ & $6.1(4.0-9.2)$ & --- & 1.6 & 1.7 & 0.4 \\
\hline $20: 0$ & $1.5(0.2-3.9)$ & --- & --- & --- & --- \\
\hline $22: 0$ & $1.0(0.1-1.9)$ & --- & --- & --- & --- \\
\hline $24: 0$ & $1.4(0.6-2.4)$ & --- & --- & --- & --- \\
\hline $16: 1$ & $1.2(0.1-5.2)$ & --- & --- & 0.0 & 0.0 \\
\hline $18: 1$ & $22.2(9.8-34.8)$ & --- & 8.7 & 7.7 & 20.3 \\
\hline $18: 2$ & $31.5(19.1-44.1)$ & --- & 23.5 & 21.5 & 15.0 \\
\hline $18: 3$ & $10.9(1.2-19.6)$ & --- & 19.7 & 33.8 & 21.0 \\
\hline $20: 1$ & $0.8(0.1-2.8)$ & --- & --- & 0.0 & 0.0 \\
\hline Saturated & $33.4(26.2-41.7)$ & --- & 25.9 & 14.5 & 20.8 \\
\hline Unsaturated & $66.6(58.3-73.8)$ & --- & 74.1 & 85.5 & 79.2 \\
\hline Monounsaturated & $24.2(10.5-39.6)$ & --- & 8.7 & 7.7 & 20.3 \\
\hline Polyunsaturated & $42.3(24.5-61.5)$ & --- & 43.1 & 55.3 & 36.0 \\
\hline
\end{tabular}

${ }^{2}$ Information from USDA Nutrient Database for Standard Reference, release 14 (http://www.nal.usda. gov/fnic/foodcomp).

${ }^{2}$ Grown in Virginia during 1997 and 1998; means over 48 observations: eight genotypes, 2 years, and three planting dates; and range.

ynformation obtained from Nabhan, 1983.

mid-June had highest concentration of 20:1 fatty acid $(1.84 \%)$ which was significantly greater than that from late May or mid-July plantings $(1.12 \%$ and $0.71 \%$, respectively). However, during 1998, planting date did not affect concentration of 20:1 fatty acid. During 1997 , the concentration of 20:1 fatty acid did not differ among eight tepary bean genotypes. Significant variation existed among eight tepary bean genotypes for the concentration of 22:0 fatty acid during 1997 but not during 1998. During 1997, concentration of 22:0 fatty acid varied from 0.34 (Neb-T-4) to $1.30 \%$ (Neb$\mathrm{T}-11)$. Concentration of 22:0 fatty acid in the seed oil of Neb-T-14, the genotype that had the highest concentration of polyunsaturated and unsaturated fatty acids, was $0.8 \%$.

The eight tepary bean genotypes had black (Neb-T-4, Neb-T-8, and Neb-T-15), tan (NebT-3, Neb-T-5, and Neb-T-14, or white (Neb-T-9 and Neb-T-11) seedcoats. The seed color was not associated with concentration of oil or fatty acids (Data not presented) except for 24:0 fatty acid in which case white-seeded genotypes had significantly higher concentration $(1.7 \%)$ over black-seeded genotypes $(1.2 \%)$. The concentration of 24:0 fatty acid in seed oil of white-seeded genotypes was $1.4 \%$.

A comparison of oil and fatty acids in tepary bean to that of navy bean, kidney bean, and pinto bean (USDA, 2004) indicated that tepary bean seeds contained higher concentrations of oil and 18:0, 18:1, 18:2, saturated, and monosaturated fatty acids, lower concentrations of 18:3 and unsaturated fatty acids, and similar concentration of 16:0 fatty acid (Table 3 ). profile of seed oil from tepary bean differed from that of established edible legumes. The data also suggested that lipids in tepary bean seeds may be less susceptible to auto-oxidation as compared to the other legumes because of lower concentration of 18:3 and total unsaturated fatty acids. We have previously reported that protein concentration of tepary bean seeds is similar to that in navy, kidney, and pinto bean seeds (Bhardwaj and Hamama, 2004). Overall, it may be concluded that, based on our results with oil and fatty acids, tepary bean has potential as a food grain. Availability of additional data from a larger sample of tepary bean lines grown over diverse environments would be needed to ascertain precise nutritional quality of tepary bean.

Based on our studies, we conclude that planting dates did notaffect oil concentration in tepary bean seeds but had significant effects on total saturated, total unsaturated, and polyunsaturated fatty acids. Later planting resulted in increased unsaturated fatty acids and decreased These results indicated that, in general, the lipid saturated fatty acids. Tepary bean genotypes did not differ for concentration of oil and many fatty acids. The concentrations of oil and most fatty acids were not associated with seedcoat color. Neb-T-14 was identified to be a desirable genotype based on concentrations of saturated, unsaturated, and poly-unsaturated fatty acids. Based on concentrations of oil and fatty acids, tepary bean seeds compared well with those of navy, kidney, and pinto beans.

\section{Literature Cited}

Bhardwaj, H.L. and A.A. Hamama. 2000. Oil, erucic acid, and glucosinolate contents in winter hardy rapeseed germplasms. Ind. Crops Products 12:33-38.

Bhardwaj, H.L. and A.A. Hamama. 2004. Protein and mineral composition of tepary bean seed. HortScience 39(6):1363-1365.

Bhardwaj, H.L., M. Rangappa, and A.A. Hamama, 2002. Planting date and genotype effects on tepary bean productivity. HortScience 37(2):317-318.

Dahmer, M.L., P.D. Fleming, G.B. Collins, and D.F. Hildebrand. 1989. A rapid screening technique for determining the lipid composition of soybean seeds. J. Amer. Oil Chem. Soc.66:543-549.

Miklas, P.N., J.C. Rosas, J.S. Beaver, L. Telek, and G.P. Freytag. 1994. Field performance of select tepary bean germplasm in the tropics. Crop Science 34:1639-1644.

Morris, D.H. 2004. Flax: A health and nutrition primer. 7 Jan. 2005. http://www.flaxcouncil. ca/primer.

Nabhan, G.P. 1983. The desert tepary as a food source. In: Frank S. Crosswhite (ed.). Desert plants. vol. 5, no. 1. Univ. Ariz. for the Boyce Thompson S.W. Arboretum, Superior.

Nabhan, G.P. and R.S. Felger. 1978. Teparies in southwestern North America. Econ. Bot. 32:2-19.

SAS. 1996. SAS system for Windows. SAS Institute, Inc., Cary, N.C.

Shukla, V.K.S. and K. Bhattacharya. 2004.Correcting $6 / 3$ balance in human diet by internally stabilised designer oil. AgroFOOD Ind. Hi-Tech 16:41-43.

Steel, R.G.D. and J.H. Torrie. 1980. Principles and Procedures of Statistics, ABiometricalApproach. McGraw-Hill Book Co., New York.

Thomas, C.V., R.M. Manshardt, and J.G. Waines. 1983. Teparies as a source of useful traits for improving common beans, p. 43-48. In: Frank S. Crosswhite (ed.). Desert Plants. vol. 5, no. 1.

U.S. Department of Agriculture. 2004. U.S. Department of Agriculture, Agricultural Research Service. 2001. USDA nutrient database for standard reference, release 14. 5 Aug. 2004. http://www. nal.usda.gov/fnic/foodcomp/search/.

Watkins, C. 2004. Fundamental fats. INFORM 15(10):638-640. 